\title{
METHODS FOR PROBABILISTIC DECISION MAKING WITH LINGUISTIC INFORMATION
}

\author{
Guiwu WEI, Xiaofei ZHAO \\ School of Economics and Management, Chongqing University of Arts and Sciences, \\ 402160 Chongqing, P. R. China
}

Received 25 September 2011; accepted 26 May 2012

\begin{abstract}
With respect to decision making problems by using probabilities, immediate probabilities and information that can be represented with linguistic labels, some new decision analysis are proposed. Firstly, we shall develop three new aggregation operators: generalized probabilistic 2-tuple weighted average (GP-2TWA) operator, generalized probabilistic 2-tuple ordered weighted average (GP-2TOWA) operator and generalized immediate probabilistic 2-tuple ordered weighted average (GIP-2TOWA) operator. These operators use the weighted average (WA) operator, the ordered weighted average (OWA) operator, linguistic information, probabilistic information and immediate probabilistic information. They are quite useful because they can assess the uncertain information within the problem by using both linguistic labels and the probabilistic information that considers the attitudinal character of the decision maker. In these approaches, alternative appraisal values are calculated by the aggregation of 2-tuple linguistic information. Thus, the ranking of alternative or selection of the most desirable alternative(s) is obtained by the comparison of 2-tuple linguistic information. Finally, we give an illustrative example about selection of strategies to verify the developed approach and to demonstrate its feasibility and practicality.
\end{abstract}

Keywords: decision making, linguistic information, probabilistic, generalized probabilistic 2-tuple weighted average (GP-2TWA) operator, generalized probabilistic 2-tuple ordered weighted average (GP-2TOWA) operator, generalized immediate probabilistic 2-tuple ordered weighted average (GIP-2TOWA) operator.

Reference to this paper should be made as follows: Wei, G.; Zhao, X. 2014. Methods for probabilistic decision making with linguistic information, Technological and Economic Development of Economy 20(2): 193-209.

JEL Classification: C02, C44, D81.

\section{Introduction}

A multiple attribute decision making problem is to find a desirable solution from a finite number of feasible alternatives assessed on multiple attributes, both quantitative and

Corresponding author Guiwu Wei

E-mail:weiguiwu@163.com

Copyright ( 2014 Vilnius Gediminas Technical University (VGTU) Press

http://www.tandfonline.com/TTED 
qualitative. In order to choose a desirable solution, decision makers often provide his/her preference information which takes the form of numerical values, such as exact values, interval number values and fuzzy numbers (Liu 2009; Zhang, Liu 2010; Han, Liu 2011; Kaya, Kahraman 2011; Yan et al. 2011; Wei 2010a, b, 2012). However, under many conditions, numerical values are inadequate or insufficient to model real-life decision problems. Indeed, human judgments including preference information may be stated in linguistic terms. Thus, multiple attribute decision making problems under linguistic environment is an interesting research topic having received more and more attention from researchers during the last several years. Several methods have been proposed for dealing with linguistic information. These methods are mainly as follows:

(1) The approximative computational model based on the Extension Principle (Degani, Bortolan 1988);

(2) The ordinal linguistic computational model (Delgado et al. 1993);

(3) The 2-tuple linguistic computational model (Herrera, Herrera-Viedma 2000a, b; Herrera et al. 2005; Herrera, Martínez 2001; Wei 2010a, b, 2011a, c; Wei, Zhao 2012).

The first models transform linguistic assessment information into fuzzy numbers and uses fuzzy arithmetic to make computations over these fuzzy numbers. The use of fuzzy arithmetic increases the vagueness. The results obtained by the fuzzy arithmetic are fuzzy numbers that usually do not match any linguistic term in the initial term set. The second models is also called symbolic model which makes direct computations on labels using the ordinal structure of the linguistic term sets. But symbolic method easily results in a loss of information caused by the use of the round operator. The third models use the 2-tuple linguistic representation and computational model to make linguistic computations. Herrera and Martínez (1991) show 2-tuple linguistic information processing manner can effectively avoid the loss and distortion of information. It has a distinct advantage over other linguistic processing methods in accuracy and reliability. Herrera, Herrera-Viedma (2000a) developed 2-tuple arithmetic average (TAA) operator, 2-tuple weighted average (TWA) operator, 2-tuple ordered weighted average (TOWA) operator and extended 2-tuple weighted average (ETWA) operator. Herrera et al. (2005) presented a group decision making process for managing non-homogeneous information. The non-homogeneous information can be represented as values belonging to domains with different nature as linguistic, numerical and interval valued or can be values assessed in label sets with different granularity, multi-granular linguistic information. Herrera-Viedma et al. (2005) presented a model of consensus support system to assist the experts in all phases of the consensus reaching process of group decision-making problems with multi-granular linguistic preference relations. Liao et al. (2007) presented a model for selecting an ERP system based on linguistic information processing. Herrera et al. (2008) proposed a fuzzy linguistic methodology to deal with unbalanced linguistic term sets. Wang (2009) presented a 2-tuple fuzzy linguistic evaluation model for selecting appropriate agile manufacturing system in relation to MC production. Tai and Chen (2009) developed a new evaluation model for intellectual capital based on computing with linguistic variable. Fan et al. (2009) Evaluated knowledge management capability of organizations by using a fuzzy linguistic method. Zhang and Chu (2009) developed fuzzy group decision making for multi-format and multi-granularity linguistic judgments in quality function deployment. 
Wei (2010a) extended TOPSIS method to 2-tuple linguistic multiple attribute group decision making with incomplete weight information. Wei (2010b) proposed a method for multiple attribute group decision making based on the ET-WG and ET-OWG operators with 2-tuple linguistic information. Fan and Liu (2010) developed a method for group decision making based on multi-granularity uncertain linguistic information. Chang and Wen (2010) developed a novel efficient approach for DFMEA combining 2-tuple and the OWA operator. Ngan (2011) took an alternative view that the result of aggregating fuzzy ratings should be fuzzy itself, and therefore they further developed the 2-tuple fuzzy linguistic methodology so that its output is a fuzzy number describing the aggregation of opinions. they demonstrated the utility of the extended fuzzy linguistic computing methodology by applying it to two data sets: (i) the evaluation of a new product idea in a Taiwanese electronics manufacturing firm and (ii) the evaluation of the investment benefit of a proposed facility site.

Another interesting approach is the use of probabilistic information in the analysis because we are able to introduce objectivity in our studies. In the literature, we find a wide range of models that use probabilistic information such as the immediate probabilities (Yager et al. 1995; Merigó 2010) and the Dempster-Shafer theory of evidence (Merigó, Casanovas 2009; Merigó et al. 2010). Recently, Merigó (2008, 2009a) has suggested the probabilistic OWA (POWA) operator. It is an aggregation operator that unifies the probability with the OWA operator considering the degree of importance that each concept has in the aggregation. Moreover, he has also suggested the probabilistic weighted average (PWA) (Merigó 2009b). Its main advantage is that it unifies the probability and the weighted average in the same formulation considering how relevant they are in the aggregation.

In this paper, we investigate the probabilistic decision making problems with linguistic information, some new probabilistic decision making methods are developed. The aim of this paper is to develop some new decision making models by using probabilities, immediate probabilities and information that can be represented with linguistic labels. Firstly, we shall develop three new aggregation operators: generalized probabilistic 2-tuple weighted average (GP-2TWA) operator, generalized probabilistic 2-tuple ordered weighted average (GP-2TOWA) operator and generalized immediate probabilistic 2-tuple ordered weighted average (GIP-2TOWA) operator. These operators use the weighted average (WA) operator, the ordered weighted average (OWA) operator, linguistic information and probabilistic information. They are quite useful because they can assess the uncertain information within the problem by using both linguistic labels and the probabilistic information that considers the attitudinal character of the decision maker. In doing so, the remainder of this paper is set out as follows. In the next section, we introduce some basic concepts and operational laws of 2-tuple linguistic variables. In Section 2 we develop some generalized probabilistic weighted average operator with linguistic assessment information, some generalized probabilistic ordered weighted average operator with linguistic assessment information and some generalized immediate probabilistic ordered weighted average operator with linguistic assessment information. In Section 3, we give an illustrative example about selection of strategies to verify the developed approach and to demonstrate its feasibility and practicality. In the final section we conclude the paper and give some remarks. 


\section{Preliminaries}

Let $S=\left\{s_{i} \mid i=1,2, \cdots, t\right\}$ be a linguistic term set with odd cardinality. Any label, $s_{i}$ represents a possible value for a linguistic variable, and it should satisfy the following characteristics (Herrera, Herrera-Viedma 2000a, b; Herrera et al. 2005; Herrera, Martínez 2001):

(1) The set is ordered: $s_{i}>s_{j}$, if $i>j$; (2) Max operator: $\max \left(s_{i}, s_{j}\right)=s_{i}$, if ..; (3) Min operator: $\min \left(s_{i}, s_{j}\right)=s_{i}$, if $s_{i} \leq s_{j}$. For example, $S$ can be defined as:

$$
\begin{gathered}
S=\left\{s_{1}=\text { extremely poor }, s_{2}=\text { very poor }, s_{3}=\text { poor }, s_{4}=\text { medium },\right. \\
\left.s_{5}=\text { good }, s_{6}=\text { very good }, s_{7}=\text { extremely good }\right\} .
\end{gathered}
$$

Herrera, Herrera-Viedma (2000a, b) developed the 2-tuple fuzzy linguistic representation model based on the concept of symbolic translation. It is used for representing the linguistic assessment information by means of a 2 -tuple $\left(s_{i}, \alpha_{i}\right)$, where $s_{i}$ is a linguistic label from predefined linguistic term set $S$ and $\alpha_{i}$ is the value of symbolic translation, and $\alpha_{i} \in[-0.5,0.5)$.

Definition 1. Let $\beta$ be the result of an aggregation of the indices of a set of labels assessed in a linguistic term set $S$, i.e. the result of a symbolic aggregation operation, $\beta \in[1, t]$, and $t$ the cardinality of $S$. Let $i=\operatorname{round}(\beta)$ and $\alpha=\beta-i$ be 2 values, such that $i \in[1, t]$ and $\alpha \in[-0.5,0.5)$; then $\alpha$ is called a symbolic translation of the aggregation (Herrera, Herrera-Viedma 2000a, b).

Definition 2. Let $S=\left\{s_{1}, s_{2}, \cdots, s_{t}\right\}$ be a linguistic term set and $\beta \in[1, t]$ be a value representing the result of a symbolic aggregation operation; then 2-tuple that expresses the equivalent information to $\beta$ is obtained with the following function:

$$
\begin{gathered}
\Delta:[1, t] \rightarrow S \times[-0.5,0.5) ; \\
\Delta(\beta)=\left\{\begin{array}{l}
s_{i} \cdot i=\operatorname{round}(\beta) \\
\alpha=\beta-i, \alpha \in[-0.5,0.5)
\end{array},\right.
\end{gathered}
$$

where: round(.) is the usual round operation; $s_{i}$ has the closest index label to $\beta$ and $\alpha$ is the value of the symbolic translation (Herrera, Herrera-Viedma 2000a, b).

Definition 3. Let $S=\left\{s_{1}, s_{2}, \cdots, s_{t}\right\}$ be a linguistic term set and $\left(s_{i}, \alpha_{i}\right)$ be a 2-tuple; a function $\Delta^{-1}$ can be defined, such that, from a 2 -tuple $\left(s_{i}, \alpha_{i}\right)$ it return its equivalent numerical value $\beta \in[1, t] \subset R$, which is obtained with the following function (Herrera, Herrera-Viedma $2000 \mathrm{a}, \mathrm{b})$ :

$$
\begin{gathered}
\Delta^{-1}: S \times[-0.5,0.5) \rightarrow[1, t] ; \\
\Delta^{-1}\left(s_{i}, \alpha\right)=i+\alpha=\beta .
\end{gathered}
$$

Definition 4. The comparison of linguistic information represented by 2-tuples is carried out according to an ordinary lexicographic order. Let $\left(s_{k}, a_{k}\right)$ and $\left(s_{l}, a_{l}\right)$ be two 2-tuples, with each one representing a linguistic assessment (Herrera, Herrera-Viedma 2000a, b):

(1) If $k<l$ then $\left(s_{k}, a_{k}\right)$ is smaller than $\left(s_{l}, a_{l}\right)$;

(2) If $k=l$ then, 1) if $a_{k}=a_{l}$, then $\left(s_{k}, a_{k}\right),\left(s_{l}, a_{l}\right)$ represents the same information; 2) if $a_{k}<a_{l}$ then $\left(s_{k}, a_{k}\right)$ is smaller than $\left.\left(s_{l}, a_{l}\right) ; 3\right)$ if $a_{k}>a_{l}$ then $\left(s_{k}, a_{k}\right)$ is bigger than $\left(s_{l}, a_{l}\right)$. 


\section{Some generalized probabilistic weighted average operator with linguistic information}

Merigó $(2008,2009$ a) developed the probabilistic weighted average (PWA) operator which is an aggregation operator that unifies the probability and the weighted average in the same formulation considering the degree of importance that each concept has in the aggregation.

Definition 5. An PWA operator of dimension $n$ is a mapping PWA: $R^{n} \rightarrow R$, such that:

$$
\operatorname{PWA}\left(a_{1}, a_{2}, \cdots, a_{n}\right)=\sum_{j=1}^{n} v_{j} a_{j}
$$

where: $\omega=\left(\omega_{1}, \omega_{2}, \cdots, \omega_{n}\right)^{T}$ be the weight vector of $a_{j}(j=1,2, \cdots, n)$, and $\omega_{j}>0, \sum_{j=1}^{n} \omega_{j}=1$, and a probabilistic weight $p_{j}>0, \sum_{j=1}^{n} p_{j}=1, v_{j}=\beta p_{j}+(1-\beta) \omega_{j}$ with $\beta \in[0,1]$ and $v_{j}$ is the weight that unifies probabilities and WAs in the same formulation, then PWA is called the probabilistic weighted average (PWA) operator. The PWA operator is monotonic, commutative, bounded and idempotent.

Merigó (2008) proposed the generalized probabilistic weighted average (GPWA) operator which is an aggregation operator that unifies the probability and the weighted average in the same formulation considering the degree of importance that each concept has in the aggregation.

Definition 6. A GPWA operator of dimension $n$ is a mapping GPWA: $R^{n} \rightarrow R$, such that:

$$
\operatorname{GPWA}\left(a_{1}, a_{2}, \cdots, a_{n}\right)=\left(\sum_{j=1}^{n} v_{j} a_{j}^{\lambda}\right)^{1 / \lambda}
$$

where: $\omega=\left(\omega_{1}, \omega_{2}, \cdots, \omega_{n}\right)^{T}$ be the weight vector of $a_{j}(j=1,2, \cdots, n)$, and $\omega_{j}>0, \sum_{j=1}^{n} \omega_{j}=1$, and a probabilistic weight $p_{j}>0, \sum_{j=1}^{n} p_{j}=1, v_{j}=\beta p_{j}+(1-\beta) \omega_{j}$ with $\beta \in[0,1]$ and $v_{j}$ is the weight that unifies probabilities and WAs in the same formulation and $\lambda$ is a parameter such that $\lambda \in(-\infty,+\infty)$.

It's obvious that GPWA operator include a wide range of aggregation operators such as the PWA, the probabilistic weighted geometric (PWG), the probabilistic weighted harmonic average (PHWA), the probabilistic weighted quadratic average (PQWA), and a lot of other cases.

\subsection{Generalized probabilistic weighted average operator with linguistic information}

In the following, we extend the GPWA operator to linguistic environment and develop the generalized probabilistic 2-tuple weighted average (GP-2TWA) operator. The GP-2TWA is an aggregation operator that unifies the probability and the weighted average in the same formulation considering the degree of importance that each concept has in the aggregation and using uncertain information represented with linguistic values. 
Definition 7. Let $\left\{\left(r_{1}, a_{1}\right),\left(r_{2}, a_{2}\right), \ldots,\left(r_{n}, a_{n}\right)\right\}$ be a set of 2-tuple, An GP-2TWA operator of dimension $n$ is a mapping GP-2TWA: $S^{n} \rightarrow S$, furthermore,

$$
\operatorname{GP-2TWA}\left(\left(r_{1}, a_{1}\right),\left(r_{2}, a_{2}\right), \ldots,\left(r_{n}, a_{n}\right)\right)=\Delta\left(\left(\sum_{j=1}^{n} v_{j} \Delta^{-1}\left(r_{j}, a_{j}\right)^{\lambda}\right)^{1 / \lambda}\right),
$$

where: $\omega=\left(\omega_{1}, \omega_{2}, \cdots, \omega_{n}\right)^{T}$ be the weight vector of $\left(r_{j}, a_{j}\right)(j=1,2, \cdots, n)$, and $\omega_{j}>0$, $\sum_{j=1}^{n} \omega_{j}=1$, and a probabilistic weight $p_{j}>0, \sum_{j=1}^{n} p_{j}=1, v_{j}=\beta p_{j}+(1-\beta) \omega_{j}$ with $\beta \in[0,1]$ and $v_{j}$ is the weight that unifies probabilities and WAs in the same formulation and $\lambda$ is a parameter such that $\lambda \in(-\infty,+\infty)$.

Especially, if $\beta=0$, then, the GP-2TWA operator reduces to the G-2TWA operator. And if $\beta=1$, it becomes the generalized probabilistic 2-tuple average (GP-2TA). Note that the GP-2TWA is monotonic, bounded and idempotent.

Remark 1. When $\lambda=1$, the GP-2TWA operator become the P-2TWA operator.

$$
\operatorname{P-2TWA}\left(\left(r_{1}, a_{1}\right),\left(r_{2}, a_{2}\right), \ldots,\left(r_{n}, a_{n}\right)\right)=\Delta\left(\sum_{j=1}^{n} v_{j} \Delta^{-1}\left(r_{j}, a_{j}\right)\right) \text {. }
$$

Note that if $\beta=0$, for all $\left(r_{i}, a_{i}\right)$, we get the 2TWA operator; if $\beta=1$, for all $\left(r_{i}, a_{i}\right)$, we get the P-2TWA operator.

Remark 2. When $\lambda=0$, the GP-2TWA operator become the probabilistic 2-tuple weighted geoemtric (P-2TWG) operator.

$$
\operatorname{P}-2 \operatorname{TWG}\left(\left(r_{1}, a_{1}\right),\left(r_{2}, a_{2}\right), \ldots,\left(r_{n}, a_{n}\right)\right)=\Delta\left(\prod_{j=1}^{n}\left(\Delta^{-1}\left(r_{j}, a_{j}\right)\right)^{v_{j}}\right) .
$$

Note that if $\beta=0$, for all $\left(r_{i}, a_{i}\right)$, we get the 2TWG operator; if $\beta=1$, for all $\left(r_{i}, a_{i}\right)$, we get the P-2TWG operator.

Remark 3. When $\lambda=-1$, the GP-2TWA operator become the probabilistic 2-tuple weighted harmonic average (P-2TWHA) operator.

$$
\begin{aligned}
& \operatorname{P-2TWHA}\left(\left(r_{1}, a_{1}\right),\left(r_{2}, a_{2}\right), \ldots,\left(r_{n}, a_{n}\right)\right)=\Delta\left(\left(\sum_{j=1}^{n} v_{j} \Delta^{-1}\left(r_{j}, a_{j}\right)^{-1}\right)^{1 /(-1)}\right)= \\
& \Delta\left(\left(\frac{v_{j}}{\Delta^{-1}\left(r_{j}, a_{j}\right)}\right)^{-1}\right)=\Delta\left(\frac{1}{\sum_{j=1}^{n} \frac{v_{j}}{\Delta^{-1}\left(r_{j}, a_{j}\right)}}\right) .
\end{aligned}
$$

Note that if $\beta=0$, for all $\left(r_{i}, a_{i}\right)$, we get the 2TWHA operator; if $\beta=1$, for all $\left(r_{i}, a_{i}\right)$, we get the P-2TWHA operator. 
Remark 4. When $\lambda=2$, the GP-2TWA operator become the probabilistic 2-tuple weighted quadratic average (P-2TWQA) operator.

$$
\operatorname{P-2TWQA}\left(\left(r_{1}, a_{1}\right),\left(r_{2}, a_{2}\right), \ldots,\left(r_{n}, a_{n}\right)\right)=\Delta\left(\left(\sum_{j=1}^{n} v_{j} \Delta^{-1}\left(r_{j}, a_{j}\right)^{2}\right)^{1 / 2}\right) \text {. }
$$

Note that if $\beta=0$, for all $\left(r_{i}, a_{i}\right)$, we get the 2TWQA operator; if $\beta=1$, for all $\left(r_{i}, a_{i}\right)$, we get the P-2TWQA operator.

\subsection{Generalized probabilistic ordered weighted average operator with linguistic information}

Another approach for unifying probabilities and OWAs in the same formulation is the probabilistic OWA (POWA) operator (Merigó 2008, 2009b). Its main advantage is that it is able to include both concepts considering the degree of importance of each case in the problem.

Definition 8. An POWA operator of dimension $n$ is a mapping PWA: $R^{n} \rightarrow R$ that has an associated weight vector $w=\left(w_{1}, w_{2}, \cdots, w_{n}\right)^{T}$ such that $w_{j}>0$ and $\sum_{j=1}^{n} w_{j}=1$, according
to the following equation:

$$
\operatorname{POWA}\left(a_{1}, a_{2}, \cdots, a_{n}\right)=\sum_{j=1}^{n} \hat{p}_{j} a_{\sigma(j)},
$$

where: $(\sigma(1), \sigma(2), \cdots, \sigma(n))$ is a permutation of $(1,2, \cdots, n)$, such that $a_{\sigma(j-1)} \geq a_{\sigma(j)}$ for all $j=2, \cdots, n$, with $\sum_{i=1}^{n} p_{i}=1$ and $p_{i} \in[0,1], \hat{p}_{j}=\beta p_{j}+(1-\beta) w_{j}$ with $\beta \in[0,1]$ and $p_{j}$ is the associated probability of $a_{\sigma(j)}$.

We shall propose the generalized probabilistic ordered weighted average (GPOWA) operator which is an aggregation operator that unifies the probability and the weighted average in the same formulation considering the degree of importance that each concept has in the aggregation.

Definition 9. A GPOWA operator of dimension $n$ is a mapping GPOWA: $R^{n} \rightarrow R$ that has an associated weight vector $w=\left(w_{1}, w_{2}, \cdots, w_{n}\right)^{T}$ such that $w_{j}>0$ and $\sum_{j=1}^{n} w_{j}=1$, ac-
cording to the following equation:

$$
\operatorname{GPOWA}\left(a_{1}, a_{2}, \cdots, a_{n}\right)=\left(\sum_{j=1}^{n} \hat{p}_{j} a_{\sigma(j)}^{\lambda}\right)^{\lambda}
$$

where: $(\sigma(1), \sigma(2), \cdots, \sigma(n))$ is a permutation of $(1,2, \cdots, n)$, such that $a_{\sigma(j-1)} \geq a_{\sigma(j)}$ for all $j=2, \cdots, n$, with $\beta \in[0,1]$ and $p_{i} \in[0,1], \hat{p}_{j}=\beta p_{j}+(1-\beta) w_{j}$ with $\beta \in[0,1]$ and $p_{j}$ is the associated probability of $a_{\sigma(j)}$ and $\lambda$ is a parameter such that $\lambda \in(-\infty,+\infty)$.

It's obvious that GPOWA operator include a wide range of aggregation operators such as the POWA, the probabilistic ordered weighted geometric (POWG), the probabilistic ordered 
weighted harmonic average (POWHA), the probabilistic ordered weighted quadratic average (POWQA), and a lot of other cases.

In the following, we extend the GPOWA operator to linguistic environment and develop the generalized probabilistic 2-tuple weighted average (GP-2TOWA) operator.

Definition 10. Let $\left\{\left(r_{1}, a_{1}\right),\left(r_{2}, a_{2}\right), \ldots,\left(r_{n}, a_{n}\right)\right\}$ be a set of 2-tuple, An GP-2TOWA operator of dimension $n$ is a mapping GP-2TOWA: $S^{n} \rightarrow S$ that has an associated weight vector $w=\left(w_{1}, w_{2}, \cdots, w_{n}\right)^{T}$ such that $w_{j}>0$ and $\sum_{j=1}^{n} w_{j}=1$. Furthermore,

$$
\operatorname{GP-2TOWA}\left(\left(r_{1}, a_{1}\right),\left(r_{2}, a_{2}\right), \ldots,\left(r_{n}, a_{n}\right)\right)=\Delta\left(\left(\sum_{j=1}^{n} \hat{p}_{j} \Delta^{-1}\left(r_{\sigma(j)}, a_{\sigma(j)}\right)^{\lambda}\right)^{1 / \lambda}\right) \text {, }
$$

where: $(\sigma(1), \sigma(2), \cdots, \sigma(n))$ is a permutation of $(1,2, \cdots, n)$, such that $\left(r_{\sigma(j-1)}, a_{\sigma(j-1)}\right) \geq$ $\left(r_{\sigma(j)}, a_{\sigma(j)}\right)$ for all $j=2, \cdots, n$, with $\sum_{i=1}^{n} p_{i}=1$ and $p_{i} \in[0,1], \hat{p}_{j}=\beta p_{j}+(1-\beta) w_{j}$ with $\beta \in[0,1]$ and $p_{j}$ is the associated probability of $\left(r_{\sigma(j)}, a_{\sigma(j)}\right)$ and $\lambda$ is a parameter such that $\lambda \in(-\infty,+\infty)$.

The GP-2TOWAoperator unifies the probability and the OWA operator in the same formulation considering the degree of importance of each concept in the aggregation. It also uses information represented in the form of linguistic values.

Remark 5. When $\lambda=1$, the GP-2TOWA operator reduces to the P-2TOWA operator.

$$
\operatorname{P-2TOWA}\left(\left(r_{1}, a_{1}\right),\left(r_{2}, a_{2}\right), \ldots,\left(r_{n}, a_{n}\right)\right)=\Delta\left(\sum_{j=1}^{n} \hat{p}_{j} \Delta^{-1}\left(r_{\sigma(j)}, a_{\sigma(j)}\right)\right) \text {. }
$$

Note that if $\beta=0$, for all $\left(r_{i}, a_{i}\right)$, we get the 2TOWA operator; if $\beta=1$, for all $\left(r_{i}, a_{i}\right)$, we get the P-2TOWA operator.

Remark 6. When $\lambda=0$, the GP-2TOWA operator reduces to the P-2TOWG operator.

$$
\text { P-2TOWG }\left(\left(r_{1}, a_{1}\right),\left(r_{2}, a_{2}\right), \ldots,\left(r_{n}, a_{n}\right)\right)=\Delta\left(\prod_{j=1}^{n}\left(\Delta^{-1}\left(r_{\sigma(j)}, a_{\sigma(j)}\right)\right)^{\hat{p}_{j}}\right) \text {. }
$$

Note that if $\beta=0$, for all $\left(r_{i}, a_{i}\right)$, we get the 2TOWG operator; if $\beta=1$, for all $\left(r_{i}, a_{i}\right)$, we get the P-2TOWG operator.

Remark 7. When $\lambda=-1$, the GP-2TOWA operator reduces to the P-2TOWHA operator.

$$
\begin{aligned}
& \text { P-2TOWha }\left(\left(r_{1}, a_{1}\right),\left(r_{2}, a_{2}\right), \ldots,\left(r_{n}, a_{n}\right)\right)=\Delta\left(\left(\sum_{j=1}^{n} \hat{p}_{j} \Delta^{-1}\left(r_{\sigma(j)}, a_{\sigma(j)}\right)^{-1}\right)^{1 /(-1)}\right)= \\
& \Delta\left(\left(\sum_{j=1}^{n} \frac{\hat{p}_{j} \Delta^{-1}\left(r_{\sigma(j)}, a_{\sigma(j)}\right)}{)^{-1}}\right)=\Delta\left(\frac{1}{\left.\sum_{j=1}^{n} \frac{\hat{p}_{j}}{\Delta^{-1}\left(r_{\sigma(j)}, a_{\sigma(j)}\right)}\right)}\right)\right.
\end{aligned}
$$


Note that if $\beta=0$, for all $\left(r_{i}, a_{i}\right)$, we get the 2TOWHA operator; if $\beta=1$, for all $\left(r_{i}, a_{i}\right)$, we get the P-2TOWHA operator.

Remark 8. When $\lambda=2$, the GP-2TOWA operator reduces to the P-2TOWQA operator.

$$
\text { P-2TWQA }\left(\left(r_{1}, a_{1}\right),\left(r_{2}, a_{2}\right), \ldots,\left(r_{n}, a_{n}\right)\right)=\Delta\left(\left(\sum_{j=1}^{n} \hat{p}_{j} \Delta^{-1}\left(r_{\sigma(j)}, a_{\sigma(j)}\right)^{2}\right)^{1 / 2}\right) \text {. }
$$

Note that if $\beta=0$, for all $\left(r_{i}, a_{i}\right)$, we get the 2TOWQA operator; if $\beta=1$, for all $\left(r_{i}, a_{i}\right)$, we get the P-2TOWQA operator.

\subsection{Generalized immediate probabilistic ordered weighted average operator with linguistic information}

The GOWA operator (Yager 2004) is a generalization of the OWA operator (Yager 1998) by using generalized means. It can be defined as follows.

Definition 11. A GOWA operator of dimension $n$ is a mapping GOWA: $R^{n} \rightarrow R$ that has an associated weight vector $w=\left(w_{1}, w_{2}, \cdots, w_{n}\right)^{T}$ such that $w_{j}>0$ and $\sum_{j=1}^{n} w_{j}=1$. Furthermore,

$$
\operatorname{GOWA}\left(a_{1}, a_{2}, \cdots, a_{n}\right)=\left(\sum_{j=1}^{n} w_{j} a_{\sigma(j)}^{\lambda}\right)^{1 / \lambda}
$$

where $(\sigma(1), \sigma(2), \cdots, \sigma(n))$ is a permutation of $(1,2, \cdots, n)$, such that $\alpha_{\sigma(j-1)} \geq \alpha_{\sigma(j)}$ for all $j=2, \cdots, n$.

Merigó (2010) develop the immediate probability (IP) which tries to include the decision maker's attitude in a probabilistic decision-making problem. The main advantage is that it is easy to apply it in almost all the probabilistic problems studied before such as in decision-making problems, actuarial sciences and statistics. Because the probabilistic information is objective but uncertain, we cannot then guarantee that the expected result is the result that will happen in the future. If we are in the situations of uncertainty (risk environments), each decision maker will have different attitudes towards the same problem.

In order to develop the analysis, Merigó (2010) used in the same formulation the weights of the OWA operator and the probabilistic information and proposed the immediate probability OWA (IP-OWA) operator. It can be defined as follows.

Definition 12. An IP-OWA operator of dimension $n$ is a mapping IP-OWA: $R^{n} \rightarrow R$, that has an associated weight vector $w=\left(w_{1}, w_{2}, \cdots, w_{n}\right)^{T}$ such that $w_{j}>0$ and $\sum_{j=1}^{n} w_{j}=1$.
Furthermore,

$$
\operatorname{IP-OWA}\left(a_{1}, a_{2}, \cdots, a_{n}\right)=\sum_{j=1}^{n} \hat{p}_{j} a_{\sigma(j)},
$$

where: $(\sigma(1), \sigma(2), \cdots, \sigma(n))$ is a permutation of $(1,2, \cdots, n)$, such that $a_{\sigma(j-1)} \geq a_{\sigma(j)}$ for all $j=2, \cdots, n, p_{j}$ is the associated probability of $a_{\sigma(j)}$, and $\hat{p}_{j}=\frac{w_{j} p_{j}}{\sum_{j=1}^{n} w_{j} p_{j}}$ 
It's worth pointing out that IP-OWA operator is a good approach for unifying probabilities and OWAs in some particular situations. But it is not always useful, especially in situations where we want to give more importance to the probabilities or to the OWA operators. In order to show why this unification does not seem to be a final model, we could also consider other ways of representing $\hat{p}_{j}$. For example, we could also use $\hat{p}_{j}=\frac{w_{j}+p_{j}}{\sum_{j=1}^{n}\left(w_{j}+p_{j}\right)}$ or other similar approaches.

Based on GOWA operator and IP-OWA operator, in the following, we shall develop the generalized immediate probability 2-tuple OWA (GIP-2TOWA) operator.

Definition 13. Let $\left\{\left(r_{1}, a_{1}\right),\left(r_{2}, a_{2}\right), \ldots,\left(r_{n}, a_{n}\right)\right\}$ be a set of 2-tuple, An GIP-2TOWA operator of dimension is a mapping GIP-2TOWA: $S^{n} \rightarrow S$, that has an associated weight vector $w=\left(w_{1}, w_{2}, \cdots, w_{n}\right)^{T}$ such that $w_{j}>0$ and $\sum_{j=1}^{n} w_{j}=1$. Furthermore,

$$
\operatorname{GIP-2TOWA}\left(\left(r_{1}, a_{1}\right),\left(r_{2}, a_{2}\right), \ldots,\left(r_{n}, a_{n}\right)\right)=\Delta\left(\left(\sum_{j=1}^{n} \hat{p}_{j} \Delta^{-1}\left(r_{\sigma(j)}, a_{\sigma(j)}\right)^{\lambda}\right)^{1 / \lambda}\right) \text {, }
$$

where: $(\sigma(1), \sigma(2), \cdots, \sigma(n))$ is a permutation of $(1,2, \cdots, n)$, such that $\left(r_{\sigma(j-1)}, a_{\sigma(j-1)}\right) \geq$ $\left(r_{\sigma(j)}, a_{\sigma(j)}\right)$ for all $j=2, \cdots, n$, each $\left(r_{i}, a_{i}\right)$ has associated a probability $p_{i}, p_{j}$ is the associated probability of $\left(r_{\sigma(j)}, a_{\sigma(j)}\right)$, and $\hat{p}_{j}=\frac{w_{j} p_{j}}{\sum_{j=1}^{n} w_{j} p_{j}}$.

It's worth pointing out that GIP-2TOWA operator is a good approach for unifying probabilities and TOWAs in some particular situations. But it is not always useful, especially in situations where we want to give more importance to the probabilities or to the TOWA operators. In order to show why this unification does not seem to be a final model, we could also consider other ways of representing $\hat{p}_{j}$. For example, we could also use $\hat{p}_{j}=\frac{w_{j}+p_{j}}{\sum_{j=1}^{n}\left(w_{j}+p_{j}\right)}$ or other similar approaches.

If we analyze different values of the parameter $\lambda$, we obtain another group of particular cases such as the usual IP-2TOWA operator, the IP-2TOWG operator, the IP-2TOWQA operator and the IP-2TOWHA operator.

Remark 9. When $\lambda=1$, the GIP-2TOWA operator becomes the IP-2TOWA operator.

$$
\operatorname{IP-2TOWA}\left(\left(r_{1}, a_{1}\right),\left(r_{2}, a_{2}\right), \ldots,\left(r_{n}, a_{n}\right)\right)=\Delta\left(\sum_{j=1}^{n} \hat{p}_{j} \Delta^{-1}\left(r_{\sigma(j)}, a_{\sigma(j)}\right)\right) .
$$


Note that if $p_{j}=1 / n$, for all $\left(r_{i}, a_{i}\right)$, we get the 2TOWA operator and if $w_{j}=1 / n$, for all $\left(r_{i}, a_{i}\right)$, we get the P-2TOWA operator.

Remark 10. When $\lambda=0$, the GIP-2TOWA operator becomes the IP-2TOWG operator.

$$
\left.\operatorname{IP-2TOWG}\left(\left(r_{1}, a_{1}\right),\left(r_{2}, a_{2}\right), \ldots,\left(r_{n}, a_{n}\right)\right)=\Delta\left(\prod_{j=1}^{n}\left(\Delta^{-1}\left(r_{\sigma(j)}, a_{\sigma(j)}\right)\right)\right)^{\hat{p}_{j}}\right) \text {. }
$$

Note that if $p_{j}=1 / n$, for all $\left(r_{i}, a_{i}\right)$, we get the 2TOWG operator and if $w_{j}=1 / n$, for all $\left(r_{i}, a_{i}\right)$, we get the P-2TOWG operator.

Remark 11. When $\lambda=-1$, the GIP-2TOWA operator becomes the IP-2TOWHA operator.

$$
\operatorname{IP-2TOWHA}\left(\left(r_{1}, a_{1}\right),\left(r_{2}, a_{2}\right), \ldots,\left(r_{n}, a_{n}\right)\right)=\Delta\left(\frac{1}{\sum_{j=1}^{n} \frac{\hat{p}_{j}}{\Delta^{-1}\left(r_{\sigma(j)}, a_{\sigma(j)}\right)}}\right) .
$$

Note that if $p_{j}=1 / n$, for all $\left(r_{i}, a_{i}\right)$, we get the 2TOWHA operator and if $w_{j}=1 / n$, for all $\left(r_{i}, a_{i}\right)$, we get the P-2TOWHA operator.

Remark 12. When $\lambda=2$, the GIP-2TOWA operator becomes the IP-2TOWQA operator.

$$
\operatorname{IP-2TOWQA}\left(\left(r_{1}, a_{1}\right),\left(r_{2}, a_{2}\right), \ldots,\left(r_{n}, a_{n}\right)\right)=\Delta\left(\left(\sum_{j=1}^{n} \hat{p}_{j} \Delta^{-1}\left(r_{\sigma(j)}, a_{\sigma(j)}\right)^{2}\right)^{1 / 2}\right) \text {. }
$$

Note that if $p_{j}=1 / n$, for all $\left(r_{i}, a_{i}\right)$, we get the 2TOWQA operator and if $w_{j}=1 / n$, for all $\left(r_{i}, a_{i}\right)$, we get the P-2TOWQA operator.

\section{Illustrative example}

In this section, we shall analyze a decision-making problem where a company is studying which strategy is the most appropriate for them (Merigó 2010). Because the environment is very uncertain, the experts in the company need to assess the available information by using linguistic information. Assume a company that operates in Europe and North America is analyzing its general policy for the next year. The board of directors has analyzed the economic situation of the company and they have found that now is a good moment to make an expansion policy to another continent in order to become more relevant in the world. They consider five possible strategies to follow: 1) $A_{1}$ : Expand to the Asian market; 2) $A_{2}$ : Expand to the African market; 3) $\mathrm{A}_{3}$ : Expand to the South American market; 4) $\mathrm{A}_{4}$ : Expand to all three continents; 5) $\mathrm{A}_{5}$ : Do not develop any expansion. In order to evaluate these strategies, the company considers that the key factor is the economic situation for the next year. Then, according to the situation, the expected benefits for the company will be different. The experts have considered five possible situations for the next year: 1) $\mathrm{S}_{1}$ : Negative growth rate; 
2) $S_{2}$ : Growth rate near 0 ; 3) $S_{3}$ : Low growth rate; 4) $S_{4}$ : Medium growth rate; 5) $S_{5}$ : High growth rate. The five possible strategies $A_{i}(i=1,2,3,4,5)$ are to be evaluated using the linguistic term set:

$$
\begin{gathered}
S=\left\{s_{1}=\operatorname{extremely} \text { poor }(E P), s_{2}=\operatorname{very} \text { poor }(V P), s_{3}=\operatorname{poor}(P), s_{4}=\operatorname{medium}(M),\right. \\
\left.s_{5}=\operatorname{good}(G), s_{6}=\operatorname{very} \operatorname{good}(V G), s_{7}=\text { extremely } \operatorname{good}(E G)\right\} .
\end{gathered}
$$

By the three decision makers under the above five situations. the expected results depending on the alternative $A_{i}$ and the situation $S_{j}$ are shown in Table 1 .

Table 1. Available information about the strategies

\begin{tabular}{cccccc}
\hline & $\mathrm{S}_{1}$ & $\mathrm{~S}_{2}$ & $\mathrm{~S}_{3}$ & $\mathrm{~S}_{4}$ & $\mathrm{~S}_{5}$ \\
\hline $\mathrm{A}_{1}$ & $\mathrm{M}$ & $\mathrm{VP}$ & $\mathrm{EG}$ & $\mathrm{G}$ & $\mathrm{VG}$ \\
$\mathrm{A}_{2}$ & $\mathrm{EP}$ & $\mathrm{VP}$ & $\mathrm{P}$ & $\mathrm{VP}$ & $\mathrm{EP}$ \\
$\mathrm{A}_{3}$ & $\mathrm{VG}$ & $\mathrm{EG}$ & $\mathrm{M}$ & $\mathrm{VG}$ & $\mathrm{EG}$ \\
$\mathrm{A}_{4}$ & $\mathrm{M}$ & $\mathrm{G}$ & $\mathrm{VG}$ & $\mathrm{EP}$ & $\mathrm{M}$ \\
$\mathrm{A}_{5}$ & $\mathrm{G}$ & $\mathrm{EP}$ & $\mathrm{P}$ & $\mathrm{VP}$ & $\mathrm{VP}$ \\
\hline
\end{tabular}

With respect to this problem, the experts in the company find probabilistic information given as follows: $P=(0.3,0.3,0.2,0.1,0.1)$. They assume that the WA, that represents the degree of importance of each state of situations, is: $\omega=(0.2,0.25,0.15,0.3,0.1)$. Note that the probabilistic information has an importance of $35 \%$ and the WA an importance of $65 \%$. Furthermore, the policy of the company is to be very pessimistic in order to obtain safety results whenever the future results are not clear. Therefore, they decide to manipulate the probabilities by using the following OWA weighting vector: $w=(0.1,0.2,0.2,0.0 .2,0.3)$. As we can see, this weighting vector seems to be conservative because it gives higher importance to the lowest result used in the last weight. Note that the company will use immediate probabilities in order to assess this problem. The results found in the immediate probabilities by using the above probabilities and weights are shown in Table 2.

Table 2. Immediate probabilities of the problem

\begin{tabular}{cccccc}
\hline & $\mathrm{S}_{1}$ & $\mathrm{~S}_{2}$ & $\mathrm{~S}_{3}$ & $\mathrm{~S}_{4}$ & $\mathrm{~S}_{5}$ \\
\hline $\mathrm{IP}_{1}$ & 0.286 & 0.429 & 0.095 & 0.095 & 0.095 \\
$\mathrm{IP}_{2}$ & 0.429 & 0.286 & 0.095 & 0.095 & 0.095 \\
$\mathrm{IP}_{3}$ & 0.316 & 0.158 & 0.316 & 0.105 & 0.105 \\
$\mathrm{IP}_{4}$ & 0.316 & 0.316 & 0.105 & 0.158 & 0.105 \\
$\mathrm{IP}_{5}$ & 0.150 & 0.450 & 0.200 & 0.100 & 0.100 \\
\hline
\end{tabular}

Firstly, we use the GP-2TWA operator to aggregate the decision information in Table 1 and probabilistic information given as $P=(0.3,0.3,0.2,0.1,0.1)$. The results are shown in Table 3. The GP-2TWA operator includes the P-2TWA operator, P-2TWG operator, P-2TWHA operator and P-2TWQA operator. 
Secondly, we use the GP-2TOWA operator to aggregate the decision information in Table 1 and probabilistic information given as $P=(0.3,0.3,0.2,0.1,0.1)$ and OWA weighting vector $W=(0.1,0.2,0.2,0.0 .2,0.3)$. The results are shown in Table 4 . The GP-2TOWA operator includes the P-2TOWA operator, P-2TOWG operator, P-2TOWHA operator and P-2TOWQA operator.

Thirdly, we use the GIP-2TOWA operator to aggregate the decision information in Table 1 and immediate probabilities information in Table 2 . The results are shown in Table 5 . The GIP-2TOWA operator includes the IP-2TOWA operator, IP-2TOWG operator, IP-2TOWHA operator and IP-2TOWQA operator.

Finally, according to the different aggregating operators, the ordering of the alternatives are shown in Table 6. Note that > means "preferred to". As we can see, depending on the aggregation operators used, the ordering of the strategies is slightly different. Therefore, depending on the aggregation operators used, the results may lead to different decisions. However, the best strategy is $A_{3}$.

Table 3. Linguistic aggregated results $(\beta=0.35)$

\begin{tabular}{ccccc}
\hline & P-2TWA & P-2TWG & P-2TWHA & P-2TWQA \\
\hline $\mathrm{A}_{1}$ & $(\mathrm{M}, 0.40)$ & $(\mathrm{M}, 0.00)$ & $(\mathrm{M},-0.42)$ & $(\mathrm{G},-0.27)$ \\
$\mathrm{A}_{2}$ & $(\mathrm{VP},-0.17)$ & $(\mathrm{VP},-0.30)$ & $(\mathrm{VP},-0.44)$ & $(\mathrm{VP},-0.04)$ \\
$\mathrm{A}_{3}$ & $(\mathrm{VG}, 0.03)$ & $(\mathrm{VG},-0.07)$ & $(\mathrm{VG},-0.18)$ & $(\mathrm{VG}, 0.12)$ \\
$\mathrm{A}_{4}$ & $(\mathrm{M},-0.09)$ & $(\mathrm{P}, 0.30)$ & $(\mathrm{P},-0.47)$ & $(\mathrm{M}, 0.28)$ \\
$\mathrm{A}_{5}$ & $(\mathrm{P},-0.39)$ & $(\mathrm{VP}, 0.21)$ & $(\mathrm{VP},-0.13)$ & $(\mathrm{P},-0.01)$ \\
\hline
\end{tabular}

Table 4. Linguistic aggregated results $(\beta=0.35)$

\begin{tabular}{ccccc}
\hline & P-2TOWA & P-2TOWG & P-2TOWHA & P-2TOWQA \\
\hline $\mathrm{A}_{1}$ & $(\mathrm{M}, 0.30)$ & $(\mathrm{M},-0.11)$ & $(\mathrm{P}, 0.47)$ & $(\mathrm{G},-0.35)$ \\
$\mathrm{A}_{2}$ & $(\mathrm{VP},-0.33)$ & $(\mathrm{VP},-0.47)$ & $(\mathrm{EP}, 0.41)$ & $(\mathrm{VP},-0.19)$ \\
$\mathrm{A}_{3}$ & $(\mathrm{VG},-0.19)$ & $(\mathrm{VG},-0.33)$ & $(\mathrm{VG},-0.47)$ & $(\mathrm{VG},-0.08)$ \\
$\mathrm{A}_{4}$ & $(\mathrm{M},-0.18)$ & $(\mathrm{P}, 0.24)$ & $(\mathrm{P},-0.50)$ & $(\mathrm{M}, 0.17)$ \\
$\mathrm{A}_{5}$ & $(\mathrm{VP}, 0.41)$ & $(\mathrm{VP}, 0.06)$ & $(\mathrm{VP},-0.23)$ & $(\mathrm{P},-0.23)$ \\
\hline
\end{tabular}

Table 5. Linguistic aggregated results

\begin{tabular}{ccccc}
\hline & IP-2TOWA & IP-2TOWG & IP-2TOWHA & IP-2TOWQA \\
\hline $\mathrm{A}_{1}$ & $(\mathrm{M},-0.29)$ & $(\mathrm{P}, 0.33)$ & $(\mathrm{P},-0.01)$ & $(\mathrm{M}, 0.09)$ \\
$\mathrm{A}_{2}$ & $(\mathrm{VP},-0.43)$ & $(\mathrm{EP}, 0.45)$ & $(\mathrm{EP}, 0.34)$ & $(\mathrm{VP},-0.30)$ \\
$\mathrm{A}_{3}$ & $(\mathrm{VG},-0.37)$ & $(\mathrm{VG},-0.50)$ & $(\mathrm{G}, 0.36)$ & $(\mathrm{VG},-0.25)$ \\
$\mathrm{A}_{4}$ & $(\mathrm{M}, 0.05)$ & $(\mathrm{M},-0.40)$ & $(\mathrm{P},-0.09)$ & $(\mathrm{M}, 0.31)$ \\
$\mathrm{A}_{5}$ & $(\mathrm{VP}, 0.20)$ & $(\mathrm{VP},-0.18)$ & $(\mathrm{VP},-0.45)$ & $(\mathrm{P},-0.39)$ \\
\hline
\end{tabular}


Table 6. Ordering of the alternative

\begin{tabular}{ll}
\hline & Ordering \\
\hline P-2TWA & $\mathrm{A}_{3}>\mathrm{A}_{1}>\mathrm{A}_{4}>\mathrm{A}_{5}>\mathrm{A}_{2}$ \\
P-2TWG & $\mathrm{A}_{3}>\mathrm{A}_{1}>\mathrm{A}_{4}>\mathrm{A}_{5}>\mathrm{A}_{2}$ \\
P-2TWHA & $\mathrm{A}_{3}>\mathrm{A}_{1}>\mathrm{A}_{4}>\mathrm{A}_{5}>\mathrm{A}_{2}$ \\
P-2TWQA & $\mathrm{A}_{3}>\mathrm{A}_{1}>\mathrm{A}_{4}>\mathrm{A}_{5}>\mathrm{A}_{2}$ \\
P-2TOWA & $\mathrm{A}_{3}>\mathrm{A}_{1}>\mathrm{A}_{4}>\mathrm{A}_{5}>\mathrm{A}_{2}$ \\
P-2TOWG & $\mathrm{A}_{3}>\mathrm{A}_{1}>\mathrm{A}_{4}>\mathrm{A}_{5}>\mathrm{A}_{2}$ \\
P-2TOWHA & $\mathrm{A}_{3}>\mathrm{A}_{1}>\mathrm{A}_{4}>\mathrm{A}_{5}>\mathrm{A}_{2}$ \\
P-2TOWQA & $\mathrm{A}_{3}>\mathrm{A}_{1}>\mathrm{A}_{4}>\mathrm{A}_{5}>\mathrm{A}_{2}$ \\
IP-2TOWA & $\mathrm{A}_{3}>\mathrm{A}_{4}>\mathrm{A}_{1}>\mathrm{A}_{5}>\mathrm{A}_{2}$ \\
IP-2TOWG & $\mathrm{A}_{3}>\mathrm{A}_{4}>\mathrm{A}_{1}>\mathrm{A}_{5}>\mathrm{A}_{2}$ \\
IP-2TOWHA & $\mathrm{A}_{3}>\mathrm{A}_{4}>\mathrm{A}_{1}>\mathrm{A}_{5}>\mathrm{A}_{2}$ \\
IP-2TOWQA & $\mathrm{A}_{3}>\mathrm{A}_{4}>\mathrm{A}_{1}>\mathrm{A}_{5}>\mathrm{A}_{2}$ \\
\hline
\end{tabular}

\section{Conclusion}

In this paper, we investigate the decision making problems by using probabilities, immediate probabilities and information that can be represented with linguistic labels and propose some new decision analysis. Firstly, we develop three new aggregation operators: generalized probabilistic 2-tuple weighted average (GP-2TWA) operator, generalized probabilistic 2-tuple ordered weighted average (GP-2TOWA) operator and generalized immediate probabilistic 2-tuple ordered weighted average (GIP-2TOWA) operator. These operators use the WA operator, the OWA operator, linguistic information, probabilistic information and immediate probabilistic information. They are quite useful because they can assess the uncertain information within the problem by using both linguistic labels and the probabilistic information that considers the attitudinal character of the decision maker. In these approaches, alternative appraisal values are calculated by the aggregation of 2-tuple linguistic information. Thus, the ranking of alternative or selection of the most desirable alternative(s) is obtained by the comparison of 2-tuple linguistic information. Finally, we give an illustrative example about selection of strategies to verify the developed approach and to demonstrate its feasibility and practicality. Theoretical analyses and numerical results all show that the method is straightforward and has no loss of information. In the future, we shall continue working in the application of the probabilistic aggregation operators with 2-tuple linguistic assessment information to other domains.

\section{Acknowledgment}

The author is very grateful to the editor and the anonymous referees and editor for their insightful and constructive comments and suggestions, which have been very helpful in 
improving the paper. The work was supported by the National Natural Science Foundation of China under Grant No.61174149 and the Humanities and Social Sciences Foundation of Ministry of Education of the People's Republic of China under Grant No.12YJC630314.

\section{References}

Chang, K. H.; Wen, T. C. 2010. A novel efficient approach for DFMEA combining 2-tuple and the OWA operator, Expert Systems with Applications 37(3): 2362-2370. http://dx.doi.org/10.1016/j.eswa.2009.07.026

Degani, R.; Bortolan, G. 1988. The problem of linguistic approximation in clinical decision making, International Journal of Approximate Reasoning 2: 143-162. http://dx.doi.org/10.1016/0888-613X(88)90105-3

Delgado, M.; Verdegay, J. L.; Vila, M. A. 1993. On aggregation operations of linguistic labels, International Journal of Intelligent Systems 8: 351-370. http://dx.doi.org/10.1002/int.4550080303

Fan, Z. P.; Feng, B.; Sun, Y. H.; Ou, W. 2009. Evaluating knowledge management capability of organizations: a fuzzy linguistic method, Expert Systems with Applications 36(2): 3346-3354. http://dx.doi.org/10.1016/j.eswa.2008.01.052

Fan, Z. P.; Liu, Y. 2010. A method for group decision-making based on multi-granularity uncertain linguistic information, Expert Systems with Applications 37(5): 4000-4008. http://dx.doi.org/10.1016/j.eswa.2009.11.016

Han, Z. S.; Liu, P. D. 2011. A fuzzy multi-attribute decision-making method under risk with unknown attribute weights, Technological and Economic Development of Economy 17(2): 246-258. http://dx.doi.org/10.3846/20294913.2011.580575

Herrera, F.; Herrera-Viedma, E. 2000a. Choice functions and mechanisms for linguistic preference relations, European Journal of Operational Research 120: 144-161. http://dx.doi.org/10.1016/S0377-2217(98)00383-X

Herrera, F.; Herrera-Viedma, E. 2000b. Linguistic decision analysis: steps for solving decision problems under linguistic information, Fuzzy Sets and Systems 115: 67-82. http://dx.doi.org/10.1016/S0165-0114(99)00024-X

Herrera, F.; Herrera-Viedma, E.; Martínez, L. 2008. A fuzzy linguistic methodology to deal with unbalanced linguistic term sets, IEEE Transactions on Fuzzy Systems 16(2): 354-370. http://dx.doi.org/10.1109/TFUZZ.2007.896353

Herrera, F.; Martínez, L. 1991. The 2-tuple linguistic computational model: advantages of its linguistic description, accuracy and consistency, International Journal of Uncertainty, Fuzziness and Knowledge-Based Systems 9: 33-49. http://dx.doi.org/10.1142/S0218488501000971

Herrera, F.; Martínez, L. 2001. A model based on linguistic 2-tuple for dealing with multigranular hierarchical linguistic contexts in multi-expert decision-making, IEEE Transactions on Systems, Man, and Cybernetics 31: 227-234. http://dx.doi.org/10.1109/3477.915345

Herrera, F.; Martínez, L.; Sánchez, P. J. 2005. Managing non-homogeneous information in group decision making, European Journal of Operational Research 166(1): 115-132. http://dx.doi.org/10.1016/j.ejor.2003.11.031

Herrera-Viedma, E.; Martinez, L.; Mata, F.; Chiclana, F. 2005. A consensus support system model for group decision-making problems with multigranular linguistic preference relations, IEEE Transactions on Fuzzy Systems 13: 644-658. http://dx.doi.org/10.1109/TFUZZ.2005.856561

Kaya, T.; Kahraman, C. 2011. A fuzzy approach to e-banking website quality assessment based on an integrated AHP-ELECTRE method, Technological and Economic Development of Economy 17(2): 313-334. http://dx.doi.org/10.3846/20294913.2011.583727 
Liao, X. W.; Li, Y.; Lu, B. 2007. A model for selecting an ERP system based on linguistic information processing, Information Systems 32(7): 1005-1017. http://dx.doi.org/10.1016/j.is.2006.10.005

Liu, P. D. 2009. Multi-attribute decision-making method research based on interval vague set and TOPSIS method, Technological and Economic Development of Economy 15(3): 453-463.

http://dx.doi.org/10.3846/1392-8619.2009.15.453-463

Merigó, J. M. 2008. New extensions to the OWA operators and their application in decision making: $\mathrm{PhD}$ thesis (in Spanish), Department of Business Administration, University of Barcelona, Spain.

Merigó, J. M. 2009a. Probabilistic decision making with the OWA operator and its application in investment management, in Proceedings of the IFSA-EUSFLAT International Conference, Lisbon, Portugal, 1364-1369.

Merigó, J. M. 2009b. The probabilistic weighted average operator and its application in decision making, in Lasker, G. E.; Hruza, P. (Eds.). Operations Systems Research \& Security of Information. The International Institute for Advanced Studies in Systems and Cybernetics, Baden-Baden, Germany, 55-58.

Merigó, J. M. 2010. Fuzzy decision making with immediate probabilities, Computers \& Industrial Engineering 58(4): 651-657. http://dx.doi.org/10.1016/j.cie.2010.01.007

Merigó, J. M.; Casanovas, M.; Martínez, L. 2010. Linguistic aggregation operators for linguistic decision making based on the Dempster-Shafer theory of evidence, International Journal of Uncertainty, Fuzziness and Knowledge-Based Systems 18(3): 287-304. http://dx.doi.org/10.1142/S0218488510006544

Merigó, J. M.; Casanovas, M. 2009. Induced aggregation operators in decision making with the Dempster-Shafer belief structure, International Journal of Intelligent Systems 24(8): 934-954. http://dx.doi.org/10.1002/int.20368

Ngan, S. C. 2011. Decision making with extended fuzzy linguistic computing, with applications to new product development and survey analysis, Expert Systems with Applications 38: 14052-14059.

Tai, W. S.; Chen, C. T. 2009. A new evaluation model for intellectual capital based on computing with linguistic variable, Expert Systems with Applications 36(2): 3483-3488. http://dx.doi.org/10.1016/j.eswa.2008.02.017

Wang, W. P. 2009. Evaluating new product development performance by fuzzy linguistic computing, Expert Systems with Applications 36(6): 9759-9766. http://dx.doi.org/10.1016/j.eswa.2009.02.034

Wei, G. W. 2010a. Extension of TOPSIS method for 2-tuple linguistic multiple attribute group decision making with incomplete weight information, Knowledge and Information Systems 25: 623-634. http://dx.doi.org/10.1007/s10115-009-0258-3

Wei, G. W. 2010b. A method for multiple attribute group decision making based on the ET-WG and ET-OWG operators with 2-tuple linguistic information, Expert Systems with Applications 37(12): 7895-7900. http://dx.doi.org/10.1016/j.eswa.2010.04.047

Wei, G. W. 2011a. FIOWHM operator and its application to multiple attribute group decision making, Expert Systems with Applications 38(4): 2984-2989. http://dx.doi.org/10.1016/j.eswa.2010.08.087

Wei, G. W. 2011b. Gray relational analysis method for intuitionistic fuzzy multiple attribute decision making, Expert Systems with Applications 38(9): 11671-11677.

http://dx.doi.org/10.1016/j.eswa.2011.03.048

Wei, G. W. 2011c. Some generalized aggregating operators with linguistic information and their application to multiple attribute group decision making, Computers \& Industrial Engineering 61(1): 32-38. http://dx.doi.org/10.1016/j.cie.2011.02.007

Wei, G. W. 2011d. Grey relational analysis method for 2-tuple linguistic multiple attribute group decision making with incomplete weight information, Expert Systems with Applications 38(5): 4824-4828. http://dx.doi.org/10.1016/j.eswa.2010.09.163

Wei, G. W. 2012. Some induced correlated aggregating operators with intuitionistic fuzzy information and their application to multiple attribute group decision making, Expert Systems with Applications 39(1): 2026-2034. http://dx.doi.org/10.1016/j.eswa.2011.08.031 
Wei, G. W.; Zhao, X. F. 2012. Some dependent aggregation operators with 2-tuple linguistic information and their application to multiple attribute group decision making, Expert Systems with Applications 39: 5881-5886. http://dx.doi.org/10.1016/j.eswa.2011.11.120

Yager, R. R. 1998. On ordered weighted averaging aggregation operators in multicriteria decision making, IEEE Transactions on Systems Man and Cybernetics 18: 183-190. http://dx.doi.org/10.1109/21.87068

Yager, R. R. 2004. Generalized OWA aggregation operators, Fuzzy Optimization and Decision Making 3: 93-107. http://dx.doi.org/10.1023/B:FODM.0000013074.68765.97

Yager, R. R.; Engemann, K. J.; Filev, D. P. 1995. On the concept of immediate probabilities, International Journal of Intelligent Systems 10: 373-397. http://dx.doi.org/10.1002/int.4550100403

Yan, M. R.; Pong, C. S.; Lo, W. 2011. Utility-based multicriteria model for evaluating BOT projects, Technological and Economic Development of Economy 17(2): 207-218.

http://dx.doi.org/10.3846/20294913.2011.580585

Zhang, X.; Liu, P. D. 2010. Method for aggregating triangular fuzzy intuitionistic fuzzy information and its application to decision making, Technological and Economic Development of Economy 16(2): 280-290. http://dx.doi.org/10.3846/tede.2010.18

Zhang, Z. F.; Chu, X. N. 2009. Fuzzy group decision-making for multi-format and multi-granularity linguistic judgments in quality function deployment, Expert Systems with Applications 36(5): 9150-9158. http://dx.doi.org/10.1016/j.eswa.2008.12.027

Guiwu WEI has a MSc and a PhD degree in applied mathematics from SouthWest Petroleum University, Business Administration from school of Economics and Management at SouthWest Jiaotong University, China, respectively. He is an Associate Professor at the Department of Economics and Management at Chongqing University of Arts and Sciences. He has published more than 90 papers in journals, books and conference proceedings including journals such as Expert Systems with Applications, Applied Soft Computing, Knowledge and Information Systems, Knowledge-based Systems, International Journal of Uncertainty, Fuzziness and Knowledge-Based Systems, Technological and Economic Development of Economy, International Journal of Computational Intelligence Systems and Information: An International Journal. He has published 1 book. He has participated in several scientific committees and serves as a reviewer in a wide range of journals including Computers \& Industrial Engineering, International Journal of Information Technology and Decision Making, Knowledge-based Systems, Information Sciences, International Journal of Computational Intelligence Systems and European Journal of Operational Research. He is currently interested in aggregation operators, decision making and computing with words.

Xiaofei ZHAO is a Lecturer at the Department of Economics and Management, Chongqing University of Arts and Sciences. He received the BE degree in management sciences and engineer from SouthWest Jiaotong University, China. He has worked for Department of Economics and Management, Chongqing University of Arts and Sciences, China as a lecturer since 2010. 